\title{
Acromegaly is associated with increased cancer risk: a survey in Italy
}

\author{
Massimo Terzolo', Giuseppe Reimondo', Paola Berchialla², Emanuele Ferrante, \\ Elena Malchiodi³, Laura De Marinis4, Rosario Pivonello5, Silvia Grottoli6, Marco Losa7,

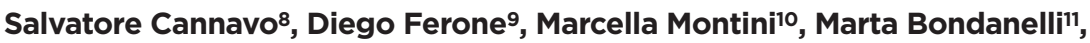 \\ Ernesto De Menis'2, Chiara Martini13, Efisio Puxeddu14, Antonino Velardo15, \\ Alessandro Peri16, Marco Faustini-Fustini17, Patrizia Tita18, Francesca Pigliaru19, \\ Giulia Peraga', Giorgio Borretta20, Carla Scaroni21, Nicoletta Bazzoni22, Antonio Bianchi4, \\ Alessandro Berton6, Andreea Liliana Serban3, Roberto Baldelli23, Letizia Maria Fatti24, \\ Annamaria Colao ${ }^{5}$ and Maura Arosio ${ }^{3}$ for the Italian Study Group of Acromegaly*
}

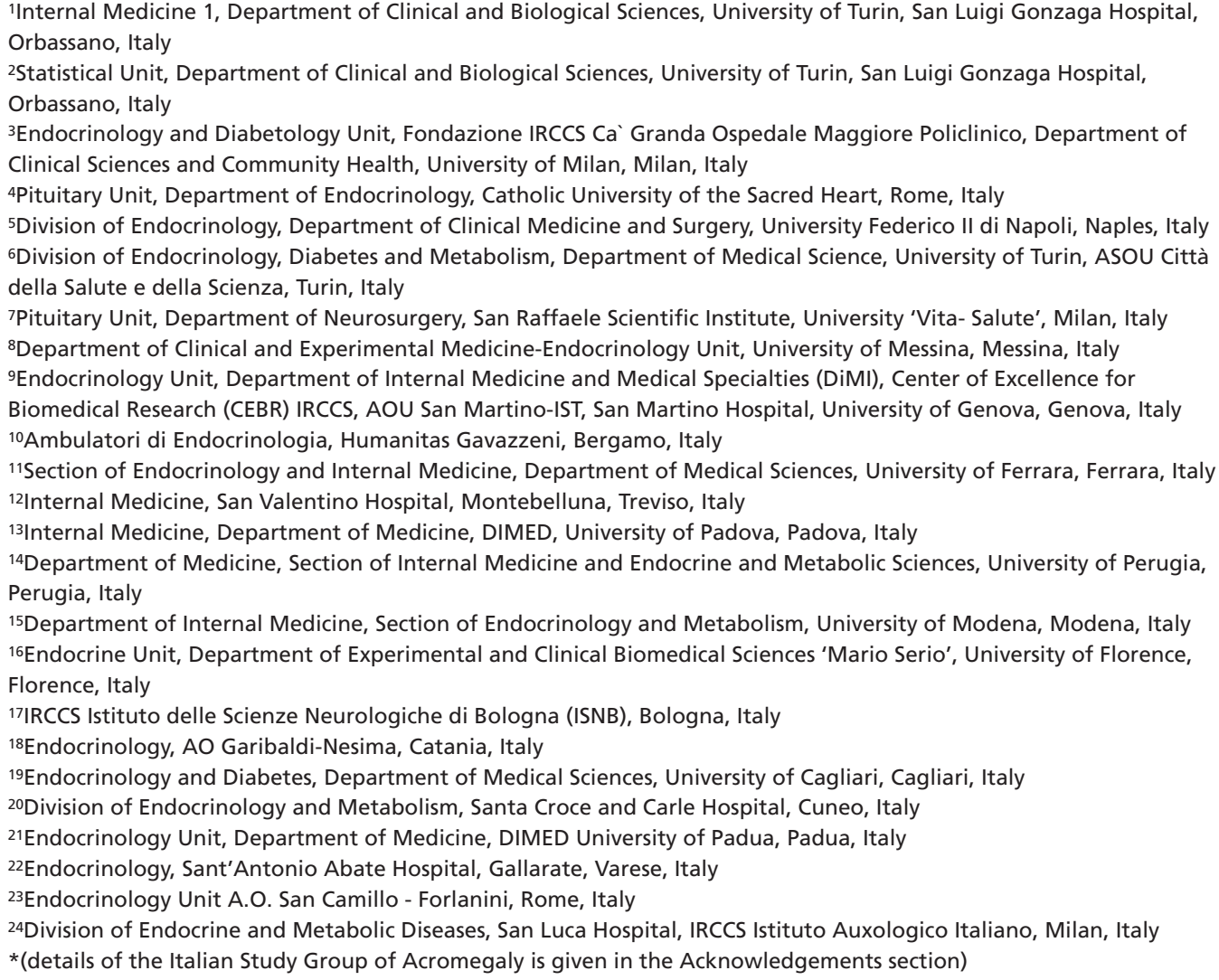

Correspondence should be addressed to $G$ Reimondo Email giuseppe.reimondo@unito.it
Abstract
It is debated if acromegalic patients have an increased risk to develop malignancies. Key Words The aim of the present study was to assess the standardized incidence ratios (SIRs) of different types of cancer in acromegaly on a large series of acromegalic patients - acromegaly managed in the somatostatin analogs era. It was evaluated the incidence of cancer in an Italian nationwide multicenter cohort study of 1512 acromegalic patients, 624 men and
- cancer
- $\mathrm{GH}$
- IGF1 
888 women, mean age at diagnosis $45 \pm 13$ years, followed up for a mean of 10 years (12573 person-years) in respect to the general Italian population. Cancer was diagnosed in 124 patients, 72 women and 52 men. The SIRs for all cancers was significantly increased compared to the general Italian population (expected: $88, \operatorname{SIR~} 1.41 ; 95 \% \mathrm{CI}$, $1.18-1.68, P<0.001)$. In the whole series, we found a significantly increased incidence of colorectal cancer (SIR 1.67; 95\% Cl, 1.07-2.58, $P=0.022$ ), kidney cancer (SIR 2.87; 95\% $\mathrm{Cl}, 1.55-5.34, P<0.001)$ and thyroid cancer (SIR 3.99; $95 \% \mathrm{Cl}, 2.32-6.87, P<0.001)$. The exclusion of 11 cancers occurring before diagnosis of acromegaly (all in women) did not change remarkably the study outcome. In multivariate analysis, the factors significantly associated with an increased risk of malignancy were age and family history of cancer, with a non-significant trend for the estimated duration of acromegaly before diagnosis. In conclusion, we found evidence that acromegaly in Italy is associated with a moderate increase in cancer risk.

\section{Introduction}

Acromegaly is an uncommon disease sustained by hypersecretion of GH and IGF1 and is associated with remarkable complications that may reduce life expectancy of these patients (Melmed 2009, Katznelson et al. 2014). However, the effective control of GH and IGF1 excess is able to reduce considerably the burden of disease. Recent population-based studies have showed that acromegalic patients have lower standard mortality ratios than previously reported (Sherlock et al. 2010), reflecting improved treatment modalities that became available in recent years, such as somatostatin-receptor ligands (SRL) and pegvisomant (Bogazzi et al. 2013, Biermasz 2014, Mercado et al. 2014) The impact of acromegaly on life expectancy comes mainly through cardiovascular and cerebrovascular events, since diabetes mellitus and hypertension are frequent complications of $\mathrm{GH}$ and IGF1 excess (Melmed 2001) Recently, we did a large-scale epidemiological analysis on 1512 acromegalic Italian patients and found that vascular disease and cancer were the main causes of death. Mortality was higher in patients with persistently active disease, and IGF1 levels at diagnosis, GH at the last follow-up, cancer and pituitary radiotherapy were independent predictors of mortality (Arosio et al. 2012).

The fact that acromegaly may cause cancer, and that mortality due to cancer contributes to shorten survival of patients with acromegaly, remains an unsolved issue (Melmed 2001, Loeper \& Ezzat 2008, Boguszewski \& Ayuk 2016). A wealth of preclinical data supports the view that the GH-IGF system plays an important role in cancer development and progression (Loeper \& Ezzat 2008, Pollak 2008, Weroha \& Haluska 2012,
Brahmkhatri et al. 2015). Moreover, in human studies, there is convincing evidence that circulating IGF1 concentrations at the higher limit of the normal range are linked with an increased risk of several types of cancers, although the excess risk seems moderate (Renehan et al. 2004, Clayton et al. 2011). Despite a sound rationale, studies that addressed the association between acromegaly and cancer produced controversial results, partly due to the different methodological approaches used (case-control and population-based design) (Loeper \& Ezzat 2008, Ayuk \& Boguszewski 2016). Moreover, it is plainly evident that most studies did not have the statistical power to demonstrate a moderate excess risk of cancer, as expected from the outcome of studies in the general population and casecontrol studies on acromegaly (Fig. 1).

A recent meta-analysis of case-control studies employing colonoscopy showed that acromegaly is associated with an increased risk of colon neoplasms, both colon adenomas, a premalignant condition that may lead to overt cancer and colon cancers. Results were consistent among the different studies with no significant heterogeneity and showed an overall excess risk of about two times (Rokkas et al. 2008). Another meta-analysis of case-control studies focusing on thyroid cancer showed an increased risk of both nodular thyroid disease and thyroid cancer in acromegaly, and again results were quite homogeneous across studies, although with less precise estimate due to the low number of events (Wolinski et al. 2014).

Population-based studies addressing cancer incidence in acromegaly produced controversial findings that 


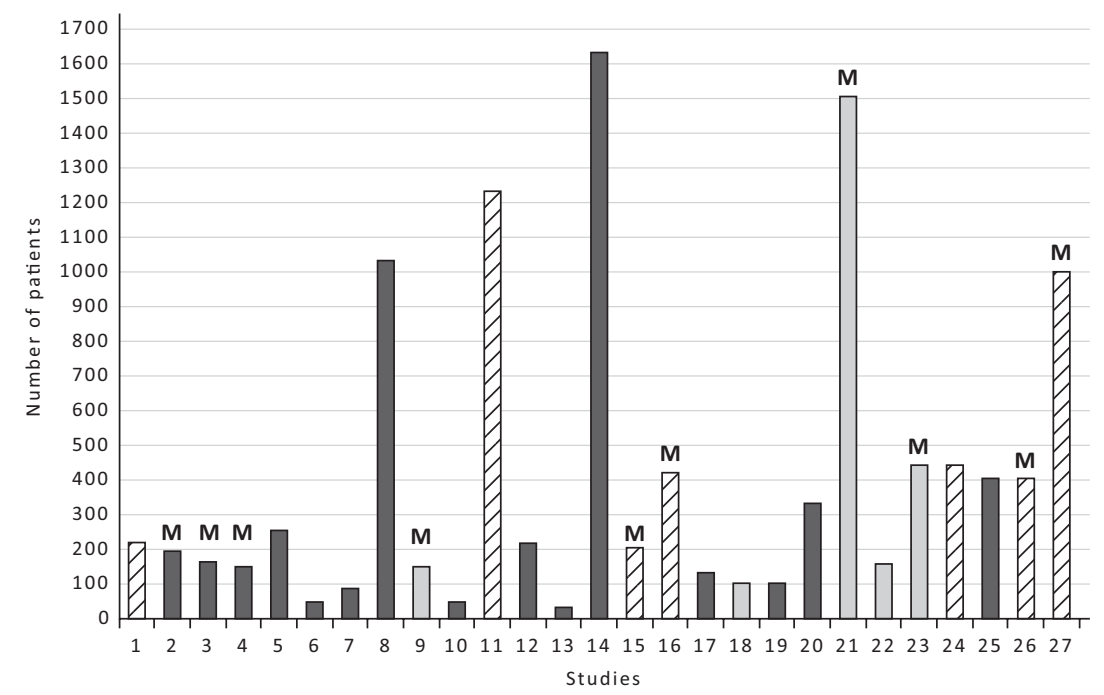

Figure 1

Sample size of the population-based studies on acromegaly and cancer. Black bars indicate studies showing a positive association between acromegaly and cancer, striped bars indicate negative studies, and white bars indicate studies that do not conclude whether an association is either present or not. Studies which focus on mortality only are marked by the letter M. 1, Mustacchi \& Shimkin (1957); 2, Wright et al. (1970); 3, Alexander et al. (1980); 4, Bengtsson et al. (1988); 5, Nabarro (1987); 6, Pines et al. (1985); 7, Barzilay et al. (1991); 8, Ron et al. (1991); 9, Rajasoorya et al. (1994); 10, Cheung \& Boyages (1997); 11, Orme et al. (1998); 12, Popovic et al. (1998); 13, Higuchi et al. (2000); 14, Baris et al. (2002); 15, Holdaway et al. (2004); 16, Ayuk et al. (2004); 17, Kurimoto et al. (2008); 18, Gullu et al. (2010); 19, Bałdys-Waligórska et al. (2010); 20, KauppinenMäkelin et al. (2010); 21, Arosio et al. (2012); 22, Dagdelen et al. (2014); 23, Mercado et al. (2014); 24, Petroff et al. (2015); 25, Cheng et al. (2015); 26, Dal et al. (2016); 27, Maione et al. (2017). may be likely explained by difference in methodology and variable sample size (Table 1). Also populationbased studies addressing whether cancer mortality may contribute to overall mortality of acromegaly came to mixed conclusions, with some studies showing an association while others did not (Table 2). However, it has been already argued that studies focusing on mortality are less helpful in answering the question whether acromegaly is associated with cancer because the prevalent cardiovascular mortality may have obscured cancer mortality. In the reported series, the median age at death was less than 60 years; thus, most patients died before they could develop clinically evident cancer (Loeper \& Ezzat 2008, Boguszewski \& Ayuk 2016).

The aim of the present study was to assess the standardized incidence ratios (SIRs) of different types of cancer in acromegaly in a nationwide multicenter cohort study in Italy on a large series of acromegalic patients who have been treated in the SRL era.

\section{Materials and methods}

\section{Subjects}

We have evaluated the prevalence of neoplasia from an Italian series of 1512 patients who were proactively followed in 24 tertiary referral centers in Italy. Patient characteristics are given in Table 3 . Inclusion criteria were age at diagnosis $>18$ years and diagnosis of acromegaly made between 1 January, 1980, and 31 December, 2002, according to standard biochemical criteria at the time of enrollment, with at least 1-year follow-up after diagnosis. The mean follow-up time from diagnosis to the end of the study was 120 months (median: 90 months; interquartile range (IQR):

Table 1 Cancer incidence data in studies with more than 200 patients.

\begin{tabular}{|c|c|c|c|}
\hline Study & $\begin{array}{l}\text { Study } \\
\text { period }\end{array}$ & $\begin{array}{c}\text { Patients } \\
\text { (no.) }\end{array}$ & $\begin{array}{l}\text { Follow-up } \\
\text { (years or } \\
\text { person-years) }\end{array}$ \\
\hline Ron et al. (1991) & 1969-1985 & $1041 *$ & 8619 \\
\hline Orme et al. (1998) & 1958-1995 & 1239 & 16778 \\
\hline Popovic et al. (1998) & 1992-1998 & 220 & 4.5 \\
\hline Baris et al. (2002) & $1965-1993$ & $1634^{*}$ & 14724 \\
\hline Kauppien-Makelin et al. (2010) & $1980-2006$ & 333 & 10.7 \\
\hline Petroff et al. (2015) & NA & 374 & 6656 \\
\hline Cheng et al. (2015) & NA & 408 & 10.2 \\
\hline Dal et al. (2016) & $1991-2010$ & 405 & 10.6 \\
\hline Maione et al. (2017) & $1977-2012$ & 999 & 6728 \\
\hline
\end{tabular}

\begin{tabular}{c} 
Age at \\
diagnosis \\
\hline NA \\
NA \\
49.5 \\
50.4 \\
47.5 \\
45.7 \\
43.2 \\
48.7 \\
43 men \\
48.5 women \\
\hline
\end{tabular}

\begin{tabular}{c} 
CANCER no., \\
$(\%)$ \\
\hline $89(8.5)$ \\
$79(6.4)$ \\
$23(10.5)$ \\
$177(10.8)$ \\
$48(14.4)$ \\
$44(11.8)$ \\
$55(13.4)$ \\
NA \\
$94(10.1 \%)$ \\
\end{tabular}

\begin{tabular}{|c|c|}
\hline SIR $(95 \% \mathrm{CI})$ & $P$ value \\
\hline $1.6(1.3-1.9)$ & NA \\
\hline $0.76(0.60-0.95)$ & 1 \\
\hline $3.39(2.12-5.12)$ & $<0.01$ \\
\hline $1.5(1.3-1.8)$ & NA \\
\hline $1.5(1.1-1.9)$ & NA \\
\hline $0.75(0.55-1.00)$ & 0.051 \\
\hline $2.87(1.57-5.25)$ & NA \\
\hline $1.4(0.9-2.2)$ & NA \\
\hline 1.34 (0.94-1.87) men & NA \\
\hline 1.24 (0.77-1.73) women & \\
\hline
\end{tabular}

NA, not available. 
Table 2 Cancer mortality data in studies with more than 150 patients.

\begin{tabular}{|c|c|c|c|c|c|c|}
\hline Study & $\boldsymbol{N}$ & $\begin{array}{l}\text { Follow-up duration } \\
\text { (years or person/years) }\end{array}$ & Age at death & Overall SMR & Cancer-related SMR $(95 \%$ CI) & $P$ value \\
\hline Nabarro (1987) & 256 & 20 & NA & 1.26 & $0.96(\mathrm{NA})$ & NA \\
\hline Bengtsson et al. (1988) & 166 & 30 & NA & NA & $\begin{array}{c}\text { Overall: } 2.68 \\
\text { Female: } 3.3 \text { (NA) }\end{array}$ & $<0.01$ \\
\hline Rajasoorya et al. (1994) & 151 & 12 & 57 & NA & 1 (NA) & NA \\
\hline Orme et al. (1998) & 1362 & NA & NA & 1.6 & $1.16(0.92-1.44)$ & 0.1 \\
\hline Ayuk et al. (2004) & 419 & 13 & NA & 1.26 & $0.91(0.59-1.39)$ & 0.65 \\
\hline Holdaway et al. (2004) & 208 & $13 \pm 9$ & $62 \pm 2$ & 1.87 & 0.92 (NA) & NA \\
\hline Dal et al. (2016) & 405 & 10.6 & $\mathrm{NA}$ & 1.3 & $1.1(0.7-1.9)$ & NA \\
\hline
\end{tabular}

$\mathrm{Cl}$, confidence interval; NA, not available; SMR, standard mortality ratio.

42-170 months). Follow-up was closed at the end of 2012. Data were collected retrospectively by local investigators in a computerized dataform developed using Access 2000 software (Microsoft) and approved by all participants. All patients gave their informed consent to the collection of data according to the local ethic committee indications. Briefly, we collected the following data for each patient: demographics, estimated date of appearance of typical acromegalic signs, GH and IGF1 levels at diagnosis and last follow-up, novel diagnosis of malignancies during follow-up, data on family history of cancer, smoking, drinking and participation in oncology screening programs. For further details on data capture and assessment see Arosio et al. (2012).

\section{Statistical analysis}

Cancer registrations were coded using the International Classification of Diseases (ICD-9), and data were compared to the general Italian population using the cancer registry AIRTUM (Associazione Italiana Registri Tumori, www.registri-tumori.it). The expected number of cancers was calculated by multiplying the number of person-years by the appropriate national, gender-, age-, calendar year- and site-specific cancer incidence rate for each five-year age group and calendar year of observation. Risks of cancer were estimated by computing the SIRs, defined as the observed to expected number of cancers for all acromegaly patients combined, and by gender, age and years of follow-up. The 95\% confidence intervals (CI) were computed assuming that the observed number follows a Poisson distribution (Liddell 1984).

Descriptive statistics were worked out. Continuous data were presented as medians and interquartile ranges or means and standard deviations. Discrete data are given as counts and percentages. Chi-square test was performed to compare categorical data between groups and the Mann-Whitney $U$ test was used to compare continuous data. Levels of significance were set at $P<0.05$.

The individual effect of patient and clinical variables on the risk of cancer was evaluated by a logistic regression

Table 3 Characteristics of the study population.

\begin{tabular}{|c|c|}
\hline & Male \\
\hline Patient number & 624 \\
\hline Age, years (median (IQR)) & $42.3(33.0,51.7)$ \\
\hline Disease duration, years (median (IQR)) & $5.0(2.0,9.0)$ \\
\hline IGF1 at diagnosis, SDS (median (IQR)) & $8.8(6.1,12.5)$ \\
\hline IGF1 at FU, SDS (median (IQR)) & $1.95(0.33,4.39)$ \\
\hline GH at diagnosis, ng/mL (median (IQR)) & $20.0(11.0,40.0)$ \\
\hline GH at FU, ng/mL (median (IQR)) & $2.0(1.0,3.7)$ \\
\hline Disease remission, $n(\%)$ & $360(62.1)$ \\
\hline Cancer familiarity, $n(\%)$ & $136(29.9)$ \\
\hline Diabetes, $n(\%)$ & $106(17.0)$ \\
\hline Radiotherapy, $n(\%)$ & $103(16.5)$ \\
\hline Cancer, $n(\%)$ & $52(8.3 \%)$ \\
\hline
\end{tabular}

\section{Sex}

\begin{tabular}{c} 
Female \\
\hline 888 \\
$47.2(37.1,55.2)$ \\
$4.5(2.0,8.0)$ \\
$8.3(5.7,12.0)$ \\
$1.11(0.04,2.80)$ \\
$18.9(9.25,35.0)$ \\
$2.0(1.0,3.8)$ \\
$572(67.5)$ \\
$216(33.9)$ \\
$139(15.6)$ \\
$166(18.7)$ \\
$72(8.1 \%)$ \\
\hline
\end{tabular}

\begin{tabular}{ccc}
\hline \multicolumn{1}{c}{ Overall } & & \\
\cline { 1 - 2 } 1512 & & $\boldsymbol{P}$ value \\
\hline $46.0(35.3,54.0)$ & & $<0.001$ \\
$5.0(3.0,8.0)$ & & NS \\
$8.5(5.8,12.3)$ & & NS \\
$1.34(0.11,3.50)$ & & $<.001$ \\
$20.0(10.0,36.0)$ & & NS \\
$2.0(1.0,3.8)$ & & NS \\
$932(65.3)$ & & 0.038 \\
$352(32.2)$ & NS \\
$245(16.2)$ & NS \\
$269(17.8)$ & NS \\
$124(8.2 \%)$ & NS
\end{tabular}

IQR, Interquartile range; NS, not significant; SDS, standard deviation score.

http://erc.endocrinology-journals.org DOI: 10.1530/ERC-16-0553
() 2017 Society for Endocrinology Printed in Great Britain 
model and a univariate estimate of the odds ratios (OR) was presented along with their 95\% CI. A multivariable model was then considered. Variables were entered into the model following a variable selection strategy, which was based on clinical judgment and statistical selection procedures. Model fit was considered as significantly improved on the basis of the Akaike Information Criterion (AIC) applied backward for each model (i.e. starting from a model with all relevant variables, eliminating those that were not significant), at a significance level of 0.05 . Interactions among variables were assessed by the Wald's test.

\section{Results}

\section{Cancer incidence}

We found 124 patients with diagnosis of cancer in our study cohort of 1512 acromegalic followed up for a mean period of 10 years (12,573 person-years). Fourteen patients had multiple cancers. Eleven subject registrations occurred before the date of diagnosis of acromegaly ( 8 breast, 2 colorectal, 1 uterus cancers) but were included in the analysis, since diagnosis of cancer preceded that of acromegaly of less than 5 years, which is within the time lag occurring between onset and clinical diagnosis of acromegaly in our cohort (Arosio et al. 2012). Raw data of observed malignancies are given in Supplementary Table 1 (see section on supplementary data given at the

Table 4 Cancer incidence data broken down by gender.

\begin{tabular}{|c|c|c|c|c|c|}
\hline Cancer type & Observed & Expected & SIR & $95 \% \mathrm{Cl}$ & $P$ value \\
\hline \multicolumn{6}{|l|}{ Female } \\
\hline $\begin{array}{l}\text { All } \\
\text { malignancies }\end{array}$ & 72 & 47.6 & 1.51 & $1.2-1.91$ & $<0.001$ \\
\hline Breast cancer & 22 & 16.8 & 1.31 & $0.86-1.99$ & 0.21 \\
\hline $\begin{array}{l}\text { Colorectal } \\
\text { cancer }\end{array}$ & 12 & 6.4 & 1.86 & $1.06-3.28$ & 0.03 \\
\hline Thyroid cancer & 8 & 2.5 & 3.22 & $1.61-6.44$ & 0.01 \\
\hline \multicolumn{6}{|l|}{ Male } \\
\hline $\begin{array}{l}\text { All } \\
\text { malignancies }\end{array}$ & 52 & 40.2 & 1.29 & $1.0-1.7$ & 0.06 \\
\hline $\begin{array}{l}\text { Colorectal } \\
\text { cancer }\end{array}$ & 8 & 5.6 & 1.44 & $0.72-2.88$ & 0.31 \\
\hline Kidney cancer & 7 & 1.9 & 3.73 & $1.78-7.83$ & $<0.001$ \\
\hline Thyroid cancer & 5 & 0.8 & 6.51 & $2.71-15.65$ & $<0.001$ \\
\hline \multicolumn{6}{|l|}{ Overall } \\
\hline $\begin{array}{l}\text { Colorectal } \\
\text { cancer }\end{array}$ & 20 & 12 & 1.67 & $1.07-2.58$ & 0.022 \\
\hline Kidney cancer & 10 & 3.5 & 2.87 & $1.55-5.34$ & $<0.001$ \\
\hline Thyroid cancer & 13 & 3.3 & 3.99 & $2.32-6.87$ & $<0.001$ \\
\hline
\end{tabular}

$\mathrm{Cl}$, confidence interval; SIR, standard incidence ratio. end of this article). In a separate analysis, we restricted SIR calculation to the malignancies observed only after the clinical diagnosis of acromegaly.

Overall, SIR for all cancers was increased compared to the general Italian population (SIR 1.41; 95\% CI, 1.18-1.68, $P<0.001)$. In the whole series, we found a significantly increased incidence of colorectal cancer (SIR 1.67; 95\% CI, 1.07-2.58, $P=0.022$ ), kidney cancer (SIR 2.87; 95\% CI, 1.55-5.34, $P<0.001$ ) and thyroid cancer (SIR 3.99; 95\% CI, 2.32-6.87, $P<0.001)$. We assessed the SIRs of different cancer types in the female and male gender, respectively (Table 4). In female patients, incidence of all malignancies was increased (SIR 1.51; 95\% CI, 1.20-1.91, $P<0.001)$, as it was incidence of thyroid cancer, colorectal cancer and breast cancer. In male patients, incidence of all malignancies was increased (SIR 1.29; 95\% CI, 1.0-1.7, $P=0.06$ ), as it was incidence of thyroid cancer, kidney cancer and colorectal cancer.

The analysis of the malignancies observed only after the clinical diagnosis of acromegaly confirmed an increased SIR for all cancers in the overall population (SIR 1.28; 95\% CI, 1.07-1.55, $P=0.007$ ). All the prevalent malignancies were observed in female patients; however, the incidence of all malignancies was still increased (SIR 1.28; 95\% CI, 1.00-1.65, $P<0.05$ ) while the incidence of breast cancer (SIR 0.83; 95\% CI, 0.50-1.41, $P=\mathrm{NS}$ ) and colorectal cancer (SIR 1.55; 95\% CI, 0.84-2.89, $P=\mathrm{NS}$ ) were not different from the general female population.

A comparable number of patients with or without cancer were submitted to proactive oncologic screening as part of their management (65\% in patients with cancer vs $60 \%$ in patients without cancer).

Table 5 Predictive factors of cancer in multivariable analysis.

\begin{tabular}{|c|c|c|}
\hline Factor & OR & $P$ value \\
\hline Age & $\begin{array}{c}5.39 \\
\text { Cl 95\%: } 2.08-13.9\end{array}$ & $<0.001$ \\
\hline Family history of cancer & $\begin{array}{c}1.73 \\
\text { Cl } 95 \%: 1.03-2.92\end{array}$ & 0.04 \\
\hline Disease duration & $\begin{array}{c}1.27 \\
\text { CI } 95 \%: 0.97-1.64\end{array}$ & 0.08 \\
\hline Pituitary radiotherapy & $\begin{array}{c}1.76 \\
\text { Cl } 95 \%: 0.89-3.45\end{array}$ & 0.10 \\
\hline Diabetes & $\begin{array}{c}1.39 \\
\mathrm{Cl} 95 \%: 0.76-2.57\end{array}$ & 0.28 \\
\hline Gender & $\begin{array}{c}1.19 \\
\text { Cl 95\%: } 0.69-2.05\end{array}$ & 0.51 \\
\hline IGF1 at last visit & $\begin{array}{c}1.03 \\
\text { Cl } 95 \%: 0.76-1.38\end{array}$ & 0.87 \\
\hline
\end{tabular}

For continuous variables, $\mathrm{OR}$ are reported for an interquartile range increase, i.e. 19 years of difference for age and 1.5 SDS for IGF1. $\mathrm{Cl}$, confidence interval; OR, odds ratio.

Published by Bioscientifica Ltd. 
Predictive factors of cancer were analyzed in univariate analysis (age, gender, duration of acromegaly before diagnosis, presence of diabetes, active disease at last follow-up, GH/IGF1 at baseline and last follow-up, pituitary radiotherapy, family history of cancer). Factors significantly associated with an increased risk of cancer were age, family history of cancer, disease duration before diagnosis, presence of diabetes and previous pituitary radiotherapy. Pertinently, we observed only 3 cases of brain cancer. In multivariable analysis, factors significantly associated with an increased risk of cancer were age and family history of cancer, while there was a non-significant trend for duration of acromegaly (Table 5).

\section{Discussion}

Whether acromegaly is associated with increased risk of cancer remains an endless debate. In general, case-control studies focusing on a specific tumor type produced more homogeneous figures, as demonstrated by a meta-analysis of colonoscopy-based studies (Rokkas et al. 2008). As casecontrol studies may lead to overestimation of risk due to ascertainment bias and problems related to matching with specific patient groups, the 'well-worried' bias, it has been suggested that population-based studies are more appropriate for assessing cancer risk (Renehan \& Brennan 2008).

However, population-based studies produced discrepant data for a number of reasons. First, due to the rarity of acromegaly, only nationwide surveys may have adequate statistical power. Second, coverage and accuracy of national cancer registries, as well as duration and completeness of follow-up, are keys for an adequate comparison with the general population. Third, the retrospective nature of these studies is an obvious limitation, particularly when considering that some studies date back to the sixties (Wright et al. 1970, Alexander et al. 1980), when treatment of acromegaly was far less effective. As a consequence, patients with uncontrolled acromegaly may have died before entering the age when cancer usually occurs; thus, competitive cardiovascular morbidity may have hindered cancer incidence and, particularly, cancer mortality (Loeper \& Ezzat 2008, Boguszewski \& Ayuk 2016).

The aim of the present study was to evaluate the incidence of cancer in a series of 1512 acromegalic patients followed up for 10 years at 24 tertiary referral centers in Italy. Most patients were treated after the introduction of SRL in clinical practice, thus representing a modern series. We found that the overall incidence of cancer was increased compared to the general population with a SIR of 1.41 (95\% CI, 1.18-1.68). The excess risk is only moderate, and this may explain why less powered studies produced controversial findings. As acromegaly is usually recognized many years after its biological onset, we included in the analysis the malignancies diagnosed within a period of 5 years prior to the clinical diagnosis of acromegaly, to account for the long period of exposure to excess GH and IGF1 preceding the diagnosis. Even if malignancies detected during this time span are considered formally as prevalent, they occur under the influence of hormone excess that is present albeit undiagnosed. Pertinently, a recent survey in Denmark identified increased morbidity over the 3 years preceding diagnosis of acromegaly (Dal et al. 2016). However, we also did a separate analysis including only the malignancies diagnosed after the clinical diagnosis of acromegaly to provide a more conservative estimate of the risk. The results of this analysis overall confirmed an excess cancer risk with the exception of breast cancer.

Only three studies in the literature have a size comparable to the present one, but only two were nationwide surveys. Ron and coworkers (Ron et al. 1991) analyzed a cohort of 1041 male inpatients with acromegaly in the United States and found an increased incidence compared to non-acromegalic hospitalized patients, who served as controls (SIR, 1.6; 95\% CI, 1.3-1.9). This increased risk was mainly attributable to gastrointestinal cancers, in particular colon cancer. However, the study may be criticized for the inclusion of only male patients admitted to hospital and for not having used tumor incidence rates of the general population as reference (Loeper \& Ezzat 2008). Orme and coworkers (Orme et al. 1998) made a large epidemiological study in the United Kingdom analyzing a cohort of 1239 subjects with acromegaly and found that the risk for all malignancies was reduced compared to the general population (SIR, 0.76; 95\% CI, 0.60-0.95), although there was a non-significant increase in the incidence of colon cancer (SIR, 1.68; $P=0.06)$. However, they excluded approximately $17 \%$ of cancer registrations that occurred before the diagnosis of acromegaly. Since the diagnosis of acromegaly is usually made years after its biological onset, excluding such cases may cause an underestimation of the phenomenon (Loeper \& Ezzat 2008, Boguszewski \& Ayuk 2016). Baris and coworkers (Baris et al. 2002) made an epidemiological study in Sweden and Denmark, analyzing a cohort of 1634 patients, and found an increased risk for
() 2017 Society for Endocrinology Printed in Great Britain
Published by Bioscientifica Ltd. 
all malignancies (SIR, 1.5; 95\% CI, 1.3-1.8), in particular of the digestive tract.

More recently, three smaller studies have been published that provided controversial results. KauppinenMäkelin and coworkers (Kauppinen-Mäkelin et al. 2010), in a nationwide survey in Finland, analyzed 334 patients and found an increased cancer incidence (SIR, 1.5; 95\% CI, 1.1-1.9). Due to the low number of events, it was impossible to make stratification per cancer type, but colon and thyroid cancers were the most frequently observed. Petroff and coworkers (Petroff et al. 2015) analyzed 446 patients from the German Acromegaly Registry and found that cancer incidence was nonsignificantly lower than the general population (SIR, $0.75 ; 95 \%$ CI, 0.55-1.00). They found a two times higher incidence of thyroid cancer in acromegalic patients that was not significant due to the low number of events. However, the study has limits in representing only a sample of the German Acromegaly Registry and in the methodology used to ascertain cancer registration, which was not always based on referring to medical records but also included phone interview. Moreover, $16 \%$ of patients were lost to follow-up. Cheng and coworkers (Cheng et al. 2015) reported on 408 acromegalic patients followed at 3 referral centers in Canada and found that cancer incidence was higher than that in the general population $(\mathrm{OR}, 2.87$; $95 \%$ CI, 1.57-5.25). In this cohort, diabetes was associated to the risk of malignancy.

The present study has strengths in the large population sample and long follow-up with all cancer registrations confirmed by the physicians who proactively managed the patients. Our study cohort was collected in many referral centers; thus, it is representative of the acromegalic population in Italy. It is also representative of a cohort treated in a modern way as demonstrated by the overall mortality data (Arosio et al. 2012) in a range comparable to those observed in more recent studies (Sherlock et al. 2010, Mercado et al. 2014, Katznelson et al. 2014). Our findings on cancer incidence are in close agreement with the nationwide survey in Finland (KauppinenMäkelin et al. 2010) that was done in the same period (SIR of the present study, 1.41; SIR of the Finnish study, 1.5). The outcome of the German study (Petroff et al. 2015), which is also a contemporary series, is at variance but the above-mentioned differences in study methodology may explain the discrepancy.

Due to our large sample size, we were able to consider separately cancer incidence between sexes and make a meaningful stratification of different cancer types. Risk of cancer was higher in women (SIR 1.51; 95\% CI, 1.20-1.91) than that in men (SIR 1.29; 95\% CI, 1.0-1.7), and this may be attributable to the fact that women were older in our series. Cancers found to be more consistently increased were thyroid cancer, kidney cancer and colorectal cancer. These findings are consistent with abundant evidence linking the IGF system with development and progression of all these cancers (Giovannucci et al. 2000, Renehan et al. 2004, Loeper \& Ezzat 2008, Pollak 2008, Clayton et al. 2011, Weroha \& Haluska 2012, Pekic \& Popovic 2013, Brahmkhatri et al. 2015).

The increased risk of colon neoplasia in acromegaly is the most widely agreed; thus, the Endocrine Society Guidelines suggested incorporating colonoscopy at diagnosis in the management of acromegaly-related comorbidities (Katznelson et al. 2014). Higher risk of breast cancer has been reported in an old study (Nabarro 1987), while recent studies found only non-significant increase in risk (Baris et al. 2002, Kauppinen-Mäkelin et al. 2010, Petroff et al. 2015). However, assessing the prevalence in acromegaly of breast cancer is particularly challenging as it may be looked at only in women, thus substantially halving the sample size. In addition, IGF1 excess could have different effects depending on the menopausal state, and on the levels of other sex and growth hormones, further increasing complexity (Renehan et al. 2004, Tworoger et al. 2011). In recent reports, there is increasing evidence that thyroid cancer is more frequent in patients with acromegaly than in control groups (Wolinski et al. 2014). A recent cross-sectional prospective study in Spain found that either benign nodular thyroid disease or thyroid cancer was more frequent in 123 patients with acromegaly than in 50 matched controls applying highly sensitive ultrasound methodology and standardized use of FNA cytology (Reverter et al. 2014). Conversely, the association between acromegaly and kidney cancer has been less frequently reported (Cheung \& Boyages 1997, Baris et al. 2002, Kauppinen-Mäkelin et al. 2010). Interestingly, expression of the IGF1 receptor has been associated with poor survival in patients with early-stage renal cancer (Parker et al. 2004).

The present study is the first to provide a multivariate analysis aiming at identifying predictors of cancer in acromegaly. We found that age and family history of cancer were significant independent factors associated to cancer risk, and these findings are biologically plausible. Moreover, a non-significant trend between cancer risk and delay in acromegaly diagnosis was apparent, but it is known that the estimate of duration of acromegaly is 
admittedly imprecise and operator dependent. We did not find evidence of an association between values of GH and IGF1, or both, and cancer risk. Orme and coworkers (Orme et al. 1998) found a higher cancer-related mortality in patients with elevated post-treatment GH, but no clear link between GH and IGF1 levels and cancer incidence in acromegaly has been definitively proven. This does not discredit the view that GH and IGF1 are implicated in cancer development in acromegaly. It has to be pointed out that the hormonal evaluation at diagnosis or at the last follow-up may give only a poor estimate of patient's exposure to GH and IGF1 in the course of a chronic disease such as acromegaly. Moreover, other factors may play important roles in determining the risk of neoplasia in acromegaly, such as insulin, insulin resistance, IGF-BP1 and BP3, obesity, body composition and leptin levels (Giovannucci et al. 2000, Melmed 2001, Tworoger et al. 2011, Pekic \& Popovic 2013, Boguszewski $\&$ Ayuk 2016). In this line, it is interesting to know that in the finding by Cheng and coworkers (Cheng et al. 2015), acromegalic patients with diabetes had more malignant tumors than non-diabetic patients. In our cohort, diabetes was associated with cancer risk only in univariate analysis. The alternative hypothesis that cancer risk in acromegaly is due to common underlining genetic factors should also be considered (Loeper \& Ezzat 2008, Renehan \& Brennan 2008, Boguszewski \& Ayuk 2016).

Limitations of our study are its retrospective nature, as for previous epidemiological studies, the consequent lack of data on the cumulative GH exposure, that has been recently suggested as a very important determinant of morbidity and mortality (Varadhan et al. 2016), and the fact that patients have been submitted in many centers to proactive oncologic screening, since previous studies conducted in Italy have suggested an association between acromegaly and colon neoplasia (Terzolo et al. 2005) or thyroid cancer (Gasperi et al. 2002, Tita et al. 2005). However, the rate of patients who underwent cancer screening was alike between patients with and without cancer; thus, it is unlikely that our findings are explained by an ascertainment bias.

In conclusion, we found evidence that acromegaly is associated with a moderate increase in cancer risk in a nationwide survey in Italy.

\section{Supplementary data}

This is linked to the online version of the paper at http://dx.doi.org/10.1530/ ERC-16-0553.

\section{Declaration of interest}

$P B, E F, E M, L D M, S G, D F, M M, M B, E D M, C M, E P, A V, M F F, P T$, $F P, G P, G B, C S, N B, A B, A B, A L S, R B, L M F, M A$ have nothing to declare. $M T$ received lecture fees from Pfizer. $G R$ received grant support from Novartis. $R$ P received grant support from Novartis, Pfizer, Ipsen. $M L$ received lecture fees from Pfizer, Ipsen. $S C$ received grant support from Novartis, Ipsen, Italfarmaco, Pfizer. A P received grant support from Novartis. A C received grant support from Novartis, Pfizer, Ipsen.

\section{Funding}

This research did not receive any specific grant from any funding agency in the public, commercial or not-for-profit sector.

\section{Acknowledgements}

Italian Study Group of Acromegaly participating centres: (1) Department of Clinical Sciences and Community Health, University of Milan, Unit of Endocrine Diseases and Diabetology, 'S. Giuseppe' Hospital, Multimedica Group (Arosio M, Montefusco L); (2) Internal Medicine 1, Department of Clinical and Biological Sciences, University of Turin, San Luigi Gonzaga Hospital, Orbassano (Angeli A, Terzolo M, Reimondo G, Zaggia B, Peraga G); (3) Department of Clinical Sciences and Community Health, University of Milan, Unit of Endocrinology and Diabetes, Fondazione IRCCS Ca` Granda Ospedale Maggiore Policlinico (Spada A, Ferrante E, Malchiodi $\mathrm{E}$, Ronchi $\mathrm{CL}$, Serban $\mathrm{AL}$ ); (4) Department of Molecular and Clinical Endocrinology and Oncology, University of Naples (Lombardi G, Colao A, Pivonello R); (5) Department of Medicine, University of Padua (Sicolo N, Martini C, Maffei P); (6) Department of Internal Medicine, Section of Endocrinology and Metabolism, University of Modena (Velardo A); (7) Department of Medicine and Pharmacology, University of Messina (Trimarchi F, Cannavo S); (8) Unit of Internal Medicine, S. Valentino Hospital, Montebelluna (Treviso) (De Menis E); (9) Pituitary Unit, Pituitary Unit, Department of Endocrinology, Catholic University of the Sacred Heart, Rome (De Marinis L, Bianchi A, Cimino V); (10) Section of Endocrinology and Internal Medicine Department of Medical Sciences, University of Ferrara (Degli Uberti EC, Ambrosio MR, Bondanelli M); (11) Division of Endocrinology, Ospedali Riuniti di Bergamo (Pagani G, Montini M, Attanasio R); (12) Department of Internal Medicine, Endocrine Unit, Bellaria Hospital, Bologna (Faustini-Fustini M, Kara E); (13) Endocrine Unit, Department of Experimental and Clinical Biomedical Sciences 'Mario Serio', University of Florence (Mannelli M, Peri A); (14) Endocrinology Unit, Department of Medicine DIMED, University Hospital of Padova (Mantero F, Scaroni C, Ceccato F); (15) Pituitary Unit, Department of Neurosurgery, San Raffaele Scientific Institute, Universita' Vita-Salute, Milan (Mortini P, Losa M); (16) Division of Endocrinology and Metabolism, S. Croce and Carle Hospital, Cuneo (Borretta G, Razzore P); (17) Department of Internal Medicine and Endocrine Sciences, University of Perugia (Angeletti G, Della Torre D, Puxeddu E); (18) Endocrinology and Diabetes, Department of Medical Sciences, University of Cagliari (Mariotti S, Pigliaru F); (19) Division of Endocrinology, Diabetology and Metabolism, Department of Internal Medicine, University of Turin (Ghigo E, Grottoli S, Berton A); (20) Endocrinology Unit, S. Antonio Abate Hospital, Gallarate, Milan (Mainini AL, Bazzoni N); (21) Endocrinology Unit, Regina Elena National Cancer Institute, Rome (Appetecchia M, Baldelli R); (22) Endocrinology, Department of Internal and Specialistic Medicine, University of Catania, Garibaldi-Nesina Hospital, Catania (Vigneri R, Tita P); (23) Endocrinology Unit, Department of Internal Medicine \& Medical Specialties (DiMI), Center of Excellence for Biomedical Research (CEBR) IRCCS, AOU San Martino-IST, S Martino Hospital, University of Genova, (Minuto F, Nazzari E, Ferone D): (24) Division of Endocrinology and Metabolic Diseases, IRCCS San Luca Hospital, Istituto Auxologico Italiano, University of Milan (Cavagnini F, Fatti L, Persani L). http://erc.endocrinology-journals.org DOI: 10.1530/ERC-16-0553
(C) 2017 Society for Endocrinology Printed in Great Britain
Published by Bioscientifica Ltd 


\section{References}

Alexander L, Appleton D, Hall R, Ross WM \& Wilkinson R 1980 Epidemiology of acromegaly in the Newcastle region. Clinical Endocrinology 12 71-79. (doi:10.1111/j.1365-2265.1980.tb03135.x)

Arosio M, Reimondo G, Malchiodi E, Berchialla P, Borraccino A, De Marinis L, Pivonello R, Grottoli S, Losa M, Cannavo S, et al. 2012 Predictors of morbidity and mortality in acromegaly: an Italian survey. European Journal of Endocrinology 167 189-198. (doi:10.1530/EJE-12-0084)

Ayuk J, Clayton RN, Holder G, Sheppard MC, Stewart PM \& Bates AS 2004 Growth hormone and pituitary radiotherapy, but not serum insulin-like growth factor- 1 concentrations, predict excess mortality in patients with acromegaly. Journal of Clinical Endocrinology and Metabolism 89 1613-1617. (doi:10.1210/jc.2003031584)

Bałdys-Waligórska A, Krzentowska A, Gołkowski F, Sokołowski G \& Hubalewska-Dydejczyk A 2010 The prevalence of benign and malignant neoplasms in acromegalic patients. Endokrynologia Polska 61 29-34.

Baris D, Gridley G, Ron E, Weiderpass E, Mellemkjaer L, Ekbom A, Olsen JH, Baron JA \& Fraumeni JF Jr 2002 Acromegaly and cancer risk: a cohort study in Sweden and Denmark. Cancer Causes and Control 13 395-400. (doi:10.1023/A:1015713732717)

Barzilay J, Heatley GJ \& Cushing GW 1991 Benign and malignant tumors in patiens with acromegaly. Archives of Internal Medicine $\mathbf{1 5 1}$ 1629-1632. (doi:10.1001/archinte.1991.00400080113022)

Bengtsson BA, Eden S, Ernest I, Oden A \& Sjogren B 1988. Epidemiology and long-term survival in acromegaly. A study of 166 cases diagnosed between 1955 and 1984. Acta Medica Scandinavica 223 327-335. (doi:10.1111/j.0954-6820.1988.tb15881.x)

Biermasz NR 2014 Pituitary gland: mortality in acromegaly reduced with multimodal therapy. Nature Reviews Endocrinology 10 708-710. (doi:10.1038/nrendo.2014.193)

Bogazzi F, Colao A, Rossi G, Lombardi M, Urbani C, Sardella C, Cannelli A, Scattina I, Manetti L, Del Sarto S, et al. 2013 Comparison of the effects of primary somatostatin analogue therapy and pituitary adenomectomy on survival in patients with acromegaly: a retrospective cohort study. European Journal of Endocrinology 169 367-376. (doi:10.1530/EJE-13-0166)

Boguszewski CL \& Ayuk J 2016 Acromegaly and cancer risk: an old debate revisited. European Journal of Endocrinology 175 147-156. (doi:10.1530/EJE-16-0178)

Brahmkhatri VP, Prasanna C \& Atreya HS 2015 Insulin-like growth factor system in cancer: novel targeted therapies. Biomedical Research International 2015538019.

Cheng S, Gomez K, Serri O, Chik C \& Ezzat S 2015 The role of diabetes in acromegaly associated neoplasia. PLOS ONE 10 e0127276. (doi:10.1371/journal.pone.0127276)

Cheung NW \& Boyages SC 1997 Increased incidence of neoplasia in females with acromegaly. Clinical Endocrinology 47 323-327. (doi:10.1046/j.1365-2265.1997.2561053.x)

Clayton PE, Banerjee I, Murray PG \& Renehan AG 2011 Growth hormone, the insulin-like growth factor axis, insulin and cancer risk. Nature Reviews Endocrinology 7 11-24. (doi:10.1038/nrendo.2010.171)

Dagdelen S, Cinar N \& Erbas T 2014 Increased thyroid cancer risk in acromegaly. Pituitary 17 299-306. (doi:10.1007/s11102-013-0501-5)

Dal J, Feldt-Rasmussen U, Andersen M, Kristensen LØ, Laurberg P, Pedersen L, Dekkers OM, Sørensen HT \& Jørgensen JO 2016 Acromegaly incidence, prevalence, complications and long-term prognosis: a nationwide cohort study. European Journal of Endocrinology 175 181-190. (doi:10.1530/EJE-16-0117)

Gasperi M, Martino E, Manetti L, Arosio M, Porretti S, Faglia G, Mariotti S, Colao AM, Lombardi G, Baldelli R, et al. 2002 Prevalence of thyroid diseases in patients with acromegaly: results of an Italian multi-center study. Journal of Endocrinological Investigation $\mathbf{2 5}$ 240-245. (doi:10.1007/BF03343997)
Giovannucci E, Pollak MN, Platz EA, Willett WC, Stampfer MJ, Majeed N, Colditz GA, Speizer FE \& Hankinson SE 2000 A prospective study of plasma insulin-like growth factor-1 and binding protein-3 and risk of colorectal neoplasia in women. Cancer Epidemiology, Biomarkers and Prevention 9 345-349.

Gullu BE, Celik O, Gazioglu N \& Kadioglu P 2010 Thyroid cancer is the most common cancer associated with acromegaly. Pituitary $\mathbf{1 3}$ 242-248. (doi:10.1007/s11102-010-0224-9)

Higuchi Y, Saeki N, Iuchi T, Uchino Y, Tatsuno I, Uchida D, Tanaka T, Noguchi Y, Nakamura S, Yasuda T, et al. 2000 Incidence of malignant tumors in patients with acromegaly. Endocrine Journal $\mathbf{4 7}$ (Supplement) 57-60. (doi:10.1507/endocrj.47.SupplMarch_S57)

Holdaway IM, Rajasoorya RC \& Gamble GD 2004 Factors influencing mortality in acromegaly. Journal of Clinical Endocrinology and Metabolism 89 667-674. (doi:10.1210/jc.2003-031199)

Katznelson L, Laws ER Jr, Melmed S, Molitch ME, Murad MH, Utz A \& Wass J 2014 Acromegaly: an Endocrine Society Clinical Practice Guideline. Journal of Clinical Endocrinology and Metabolism 99 3933-3951. (doi:10.1210/jc.2014-2700)

Kauppinen-Mäkelin R, Sane T, Välimäki MJ, Markkanen H, Niskanen L, Ebeling T, Jaatinen P, Juonala M \& Finnish Acromegaly Study Group, Pukkala 2010 Increased cancer incidence in acromegaly - a nationwide survey. Clinical Endocrinology 72 278-279.

Kurimoto M, Fukuda I, Hizuka N \& Takano K 2008 The prevalence of benign and malignant tumors in patients with acromegaly at a single institute. Endocrine Journal 55 67-71. (doi:10.1507/endocrj. K07E-010)

Liddell FD 1984 Simple exact analysis of the standardised mortality ratio. Journal of Epidemiology and Community Health 38 85-88. (doi:10.1136/jech.38.1.85)

Loeper S \& Ezzat S 2008 Acromegaly: re-thinking the cancer risk. Reviews in Endocrine and Metabolic Disorders 9 41-58. (doi:10.1007/s11154007-9063-z)

Maione L, Brue T, Beckers A, Delemer B, Petrossians P, Borson-Chazot F, Chabre O, François P, Bertherat J, Cortet-Rudelli C, et al. 2017 Changes in the management and comorbidities of acromegaly over three decades: the French Acromegaly Registry. European Journal of Endocrinology 176 645-655. (doi:10.1530/EJE-16-1064)

Melmed S 2001 Acromegaly and cancer: not a problem? Journal of Clinical Endocrinology and Metabolism 86 2929-2934. (doi:10.1210/ jcem.86.7.7635)

Melmed S 2009 Acromegaly pathogenesis and treatment. Journal of Clinical Investigation 119 3189-3202. (doi:10.1172/JCI39375)

Mercado M, Gonzalez B, Vargas G, Ramirez C, De los Monteros AL, Sosa E, Jervis P, Roldan P, Mendoza V, Lopez-Félix B, et al. 2014 Successful mortality reduction and control of comorbidities in patients with acromegaly followed at a highly specialized multidisciplinary clinic. Journal of Clinical Endocrinology and Metabolism 99 4438-4446. (doi:10.1210/jc.2014-2670)

Mustacchi P \& Shimkin MB 1957 Occurrence of cancer in acromegaly and in hypopituitarism. Cancer 10 100-104. (doi:10.1002/10970142(195701/02)10:1<100::AID-CNCR2820100113>3.0.CO;2-V)

Nabarro JD 1987 Acromegaly. Clinical Endocrinology 26 481-512. (doi:10.1111/j.1365-2265.1987.tb00805.x)

Orme SM, McNally RJ, Cartwright RA \& Belchetz PE 1998 Mortality and cancer incidence in acromegaly: a retrospective cohort study. United Kingdom Acromegaly Study Group. Journal of Clinical Endocrinology and Metabolism 83 2730-2734. (doi:10.1210/ jc.83.8.2730)

Parker AS, Cheville JC, Blute ML, Igel T, Lohse CM \& Cerhan JR 2004 Pathologic T1 clear cell renal cell carcinoma: insulin-like growth factor-I receptor expression and disease-specific survival. Cancer 100 2577-2582. (doi:10.1002/cncr.20322)

Pekic S \& Popovic V 2013 GH therapy and cancer risk in hypopituitarism: what we know from human studies. European Journal of Endocrinology 169 R89-R97. (doi:10.1530/EJE-13-0389) 
Petroff D, Tönjes A, Grussendorf M, Droste M, Dimopoulou C, Stalla G, Jaursch-Hancke C, Mai M, Schopohl J \& Schöfl C 2015 The incidence of cancer among acromegaly patients: results from the German acromegaly registry. Journal of Clinical Endocrinology and Metabolism 100 3894-3902. (doi:10.1210/jc.2015-2372)

Pines A, Rozen P, Ron E \& Gilat T 1985 Gastrointestinal tumors in acromegalic patients. American Journal of Gastroenterology 80 266-269.

Pollak M 2008 Insulin and insulin-like growth factor signalling in neoplasia. Nature Reviews Cancer 8 915-928. (doi:10.1038/nrc2536)

Popovic V, Damjanovic S, Micic D, Nesovic M, Djurovic M, Petakov M, Obradovic S, Zoric S, Simic M, Penezic, et al. 1998 Increased incidence of neoplasia in patients with pituitary adenoma. The Pituitary Study Group. Clinical Endocrinology 49 441-445. (doi:10.1046/j.1365-2265.1998.00536.x)

Rajasoorya C, Holdaway IM, Wrightson P, Scott DJ \& Ibbertson HK 1994 Determinants of clinical outcome and survivial in acromegaly. Clinical Endocrinology 41 95-102. (doi:10.1111/j.1365-2265.1994.tb03789.x)

Renehan AG \& Brennan BM 2008 Acromegaly, growth hormone and cancer risk. Best practice, research. Clinical Endocrinology, Metabolism 22 639-657. (doi:10.1016/j.beem.2008.08.011)

Renehan AG, Zwahlen M, Minder C, O'Dwyer ST, Shalet SM \& Egger M 2004 Insulin-like growth factor (IGF)-I, IGF binding protein-3, and cancer risk: systematic review and meta-regression analysis. Lancet 363 1346-1353. (doi:10.1016/S0140-6736(04)16044-3)

Reverter JL, Fajardo C, Resmini E, Salinas I, Mora M, Llatjós M, Sesmilo G, Rius F, Halperin I, Webb SM, et al. 2014 Benign and malignant nodular thyroid disease in acromegaly. Is a routine thyroid ultrasound evaluation advisable? PLOS ONE 9 e104174. (doi:10.1371/journal.pone.0104174)

Rokkas T, Pistiolas D, Sechopoulos P, Margantinis G \& Koukoulis G 2008 Risk of colorectal neoplasm in patients with acromegaly: a meta-analysis. World Journal of Gastroenterology 14 3484-3489. (doi:10.3748/wjg.14.3484)
Ron E, Gridley G, Hrubec Z, Page W, Arora S \& Fraumeni JF Jr 1991 Acromegaly and gastrointestinal cancer. Cancer 68 1673-1677. (doi:10.1002/1097-0142(19911015)68:8<1673::AIDCNCR2820680802>3.0.CO;2-0)

Sherlock M, Ayuk J, Tomlinson J, Toogood AA, Aragon-Alonso A, Sheppard MC, Bates AS \& Stewart PM 2010 Mortality in patients with pituitary disease. Endocrine Reviews 31 301-342. (doi:10.1210/er.20090033)

Terzolo M, Reimondo G, Gasperi M, Cozzi R, Pivonello R, Vitale G, Scillitani A, Attanasio R, Cecconi E, Daffara F, et al. 2005 Colonoscopic screening and follow-up in patients with acromegaly: a multicenter study in Italy. Journal of Clinical Endocrinology and Metabolism 90 84-90. (doi:10.1210/jc.2004-0240)

Tita P, Ambrosio MR, Scollo C, Carta A, Gangemi P, Bondanelli M, Vigneri R, degli Uberti EC \& Pezzino V 2005 High prevalence of differentiated thyroid carcinoma in acromegaly. Clinical Endocrinology 63 161-167. (doi:10.1111/j.1365-2265.2005.02316.x)

Tworoger SS, Rosner BA, Willett WC \& Hankinson SE 2011 The combined influence of multiple sex and growth hormones on risk of postmenopausal breast cancer: a nested case-control study. Breast Cancer Research 13 R99. (doi:10.1186/bcr3040)

Varadhan L, Reulen RC, Brown M \& Clayton RN 2016 The role of cumulative growth hormone exposure in determining mortality and morbidity in acromegaly: a single centre study. Pituitary 19 251-261. (doi:10.1007/s11102-015-0700-3)

Weroha SJ \& Haluska P 2012 The insulin-like growth factor system in cancer. Endocrinology Metabolism Clinics of North America 41 335-350. (doi:10.1016/j.ecl.2012.04.014)

Wolinski K, Czarnywojtek A \& Ruchala M 2014 Risk of thyroid nodular disease and thyroid cancer in patients with acromegaly - metaanalysis and systematic review. PLOS ONE 9 e8878.

Wright AD, Hill DM, Lowy C \& Fraser TR 1970 Mortality in acromegaly. Quarterly Journal of Medicine 39 1-16.

Received in final form 18 June 2017

Accepted 13 July 2017

Accepted Preprint published online 14 July 2017
() 2017 Society for Endocrinology Printed in Great Britain
Published by Bioscientifica Ltd 